\title{
An unprecedented outbreak of pelagic molluscs Creseis acicula in Daya Bay, South China Sea
}

\author{
Ming Dai ${ }^{1}$, Zhanhui $\mathrm{Qi}^{1}$, Lei Zeng ${ }^{1}$, Shufei Zhang ${ }^{1}$, Lingling Wang ${ }^{1}$, Xiaoqing Qin ${ }^{1}$, Xiuli \\ Liao $^{1}$, Jing Yan ${ }^{2}$, Honghui Huang ${ }^{1}$, and Shaoling Shang ${ }^{2}$ \\ ${ }^{1}$ South China Sea Fisheries Research Institute \\ ${ }^{2}$ Xiamen University
}

August 22, 2020

\begin{abstract}
Creseis acicula is a pteropod species, widely distributed in the world's ocean. The latest report of its bloom was in the Mediterranean Sea in 1990. On June 12, 2020, an unprecedented bloom of C. acicula was observed in Daya Bay, China, that lasted for over a month and caused economic losses. The maximum abundance of C. acicula was up to 5595 ind. m-3, 1000 times the local record high, and 10 times the highest number recorded elsewhere. Higher abundance ([?] 1000 ind. m-3) was found in the warm water of [?] 30 along the southwest shore of Daya Bay. The initiation of the bloom matched a sharp increase of temperature and chlorophyll a and an abrupt decrease of salinity attributed to heavy rainfall that lasted for more than 20 days. Considering rising occurrences of extreme weather due to global change, possibilities of recurrent C. acicula blooms worldwide certainly deserve attention.
\end{abstract}

\section{INTRODUCTION}

Over the last several decades, the world's ocean and inland waters have been experiencing enormous blooms of various kinds of micro- and macro-algae and zooplankton, which have caused severe environmental and economic losses. The most reported blooms in scientific papers and media include cyanobacteria (e.g., Shi et al., 2017; Huisman et al., 2018), dinoflagellates (e.g., Glibert et al., 2008, 2009; Zhou et al., 2008), Sargassum (e.g., Schell et al., 2015; Wang et al., 2019), Ulva (e.g., Smetacek and Zingone 2013; Wang et al., 2015), jellyfish (e.g., Richardson et al., 2009; Jackson et al., 2001; Sun et al., 2015), andAcetes chinesis (Zeng et al., 2019). These blooms are widespread and recurrent and have been attributed to eutrophication as well as altered environmental conditions due to climate change and anthropogenic activities (e.g., Anderson et al., 2002; Edwards et al., 2006; Heisler et al., 2008).

Creseis acicula (Rang 1828) is a pteropod species, which widespread in the world oceans and prefers warm waters, particularly in the upper layers of the ocean ranging from $50^{\circ} \mathrm{N}-40^{\circ} \mathrm{S}$ (Albergoni, 1975). Outbreaks of C. acicula were found in Indian seas (Krishna Murthy, 1967; Sakthivel and Haridas, 1974; Peter and Paulinose, 1978; Pillai and Rodrigo, 1984; Naomi, 1988), Mediterranean sea (Burgi et al., 1962; Albergoni, 1975; Kokelj et al., 1994), Japan sea (Nishimura, 1965; Morioka, 1980), and Gulf of Mexico (Hutton, 1960), occurring during the 1960s to 1990s. The last report of C. acicula bloom was in 1990 in the Mediterranean sea (Kokelj et al., 1994). Since the 1990s, for thirty years, there has not been a single record of its outbreak worldwide, until mid-June 2020, when a sudden outbreak happened in Daya Bay, South China Sea (Fig. 1, 3). This bloom of C. acicula was first observed on June 12, 2020, and persisted into July 2020. It has caused losses to local industry and tourism, particularly the Daya Bay Nuclear Power Plant (DNPP) built on the southwest shore, with highly concentrated $C$. acicula disrupting the cooling system. Both government and public attached great importance to this bloom, since it has poses a potential threat to the normal operation and safety of DNPP. 
Here we present a briefing of this unusual outbreak by summarizing our observations of the bloom and its associated environmental conditions to provide a big picture of this rare zooplankton bloom. This report would facilitate further investigations and advocate attention to possible recurrent aggregation of $C$. acicula and other organisms in the ocean, particularly in the context of global warming.

\section{METHODS}

Daya Bay is a shallow embayment with depths ranging from 5-20 m and an area of $650 \mathrm{~km}^{2}$, located in the northern South China Sea. On June 12, 2020, a huge mass of C. acicula was spotted in the waters close to the southwest shore of Daya Bay. Afterward, biological and environmental surveys in the entire Daya Bay were conducted from July 4 to 18, 2020. C. acicula was collected using vertical hauls of a plankton net (mouth diameter of $0.5 \mathrm{~m}$ and mesh size of $505 \mu \mathrm{m}$ ) from $1 \mathrm{~m}$ above the bottom to the surface. The filtered water volume was determined by the rope length multiplied by the net mouth size. Collected C. acicula was immediately taken back to the laboratory for subsequent abundance counting and biological parameter measurements, which included shell length, diameter at the aperture, and body weight. Environmental factors of surface water temperature, salinity, $\mathrm{pH}$, DO were measured in situ using a YSI 6600 multiparameter water quality monitor (Yellow Springs Instrument Co., Ohio, USA). Daily mean surface water temperature, salinity, and chlorophyll $a(\mathrm{Chl} a)$ in May-July were obtained from a maritime buoyage system located in southwestern Daya Bay (see the buoy's location in Fig. 3). The buoyage system record these data at an interval of half-hour. Historical data of C. acicula abundance in Daya Bay is from Xu (1985) and from an ocean observatory program of South China Sea Fisheries Research Institute (SCSFRI), which has been carried out every year since 2011.

\section{RESULTS}

The shell length of C. acicula collected in Daya Bay ranged from 4.13 to $14.72 \mathrm{~mm}$ (averaged $9.60 \pm 2.17$ $\mathrm{mm}$ ), similar to that observed in Indian seas and Japan seas (ranged from 9 to $12 \mathrm{~mm}$ ) (Nishimura, 1965; Pillai and Rodtigo, 1984). The diameter at the aperture ranged from 0.25 to $1.27 \mathrm{~mm}$ (averaged $0.86 \pm 0.25$ $\mathrm{mm}$ ). The body weight ranged from 2 to $3.8 \mathrm{mg}$ ind. ${ }^{-1}$ (averaged $2.8 \pm 0.6 \mathrm{mg}$ ind.- ${ }^{-1}$ ). On July 5 , it was observed that the highest proportion in the population was from individuals with a shell length of 9 to 10 $\mathrm{mm}$, and the accumulated percentage of individuals with shell length [?]10 $\mathrm{mm}$ was $72 \%$, indicating that the majority of the population were juveniles (Fig. 2). Such a population constitution suggested that the $C$. acicula bloom would keep going on after July 4, as long as environmental conditions (e.g., water temperature, salinity, and food) are favorable. Indeed, the bloom lasted in the subsequent 10 days and finally faded on July 13, when the population abundance dramatically decreased $\left(<33\right.$ ind. $\left.\mathrm{m}^{-3}\right)$, and lots of empty shells of C. acicula were observed in the sediments, as after the animals' death their empty shells settle to the sea floor.

The bloom peaked from July 4 to July 8, according to our field measurements. Higher abundance was found in the waters along the southwest coast of the Daya Bay and the highest record of abundance occurred on July 5 (Fig. 3). The average abundance of C. aciculawas 1851 ind. $\mathrm{m}^{-3}$ alongshore the southwest Daya Bay, i.e., Stations S2-S7, more than half of which were of an abundance higher than 1000 ind. $\mathrm{m}^{-3}$, and Station S5 is exactly the site recorded the highest abundance ( 5595 ind. $\mathrm{m}^{-3}$ ) throughout the entire survey. For other stations in southwestern Daya Bay (i.e., other than Stations S2-S7), the abundance of C. acicula ranged from 328 to 2278 ind. $\mathrm{m}^{-3}$, with the highest value found at Station S17. In contrast, no C. acicula accumulation was observed either in the northern and eastern areas, the mouth of Daya Bay, or in the adjacent Mirs Bay (see the green squares in Fig. 3).

\section{DISCUSSION}

C. acicula is a common species widely distributed in the world's ocean. Its abundance is usually very low in Daya Bay. According to results from Xu (1985) and our annual routine monitoring in Daya Bay since 2011, the average abundance of $C$. acicula in the bay ranged from 0.04 to 1.9 ind. $\mathrm{m}^{-3}$ (Fig. 4). The highest abundance ever recorded was 5.0 ind. $\mathrm{m}^{-3}$ at a single station in September 2012. However, during this bloom, a maximum abundance of 5595 ind. $\mathrm{m}^{-3}$ was recorded, which is 1000 times of the highest value in 
historical documents of Daya Bay. Also, this maximum value in Daya Bay is much higher those reported in Indian seas, for example, 372 ind. $\mathrm{m}^{-3}$ in Cochin in 1973 (Sakthivel and Haridas, 1974) and 474.8 ind. $\mathrm{m}^{-3}$ in Bengal Bay in 1977 (Peter and Paulinose, 1978).

Taken together, this bloom in Daya Bay in 2020 is an extreme event. What could have caused such a severe outbreak of $C$. acicula? Generally, the outbreak of a marine animal population needs to meet at least several conditions at the same time, including suitable environmental conditions (e.g., temperature and salinity), a reduction of predators and/or competitors, adequate food, and a high self-reproduction capacity.

\section{Temperature}

Temperature is the main factor governing the distribution of pteropods. They prefer a warmer water, as there is a well-defined latitudinal temperature gradient for their distribution. There is only one pteropod species, Limacina helicina Phipps lived in the two polar seas, whereas the warm, tropical zones are populated by many genera and species. Here in Daya Bay, as shown in Fig. 5, there was a positive relationship between the spatial distribution of $C$. acicula and water temperature, indicating $C$. acicula also favor of warmer water. The highest abundance (5595 ind. $\mathrm{m}^{-3}$ ) matched the highest temperature ( $\left.\sim 32.3 \mathrm{degC}\right)$. Also, most of the stations with higher abundance of $C$. acicula were located in areas with sea surface temperature [?]30degC. Furthermore, according to buoy measurements from May to July 2020 (Fig. 6), there were two peaks of sea surface temperature (SST), the first one was in June when the surface water temperature increased from $29.8 \mathrm{degC}$ on June 9 to $32.8 \operatorname{deg} \mathrm{C}$ on June 13, 2020; the second one was on July 2 when the temperature increased to $32.4 \mathrm{degC}$. It is worth noting that the observed high abundance of C. acicula population were coincident with the two temperature peaks. In fact, the bloom was observed on June 12, 2020, right falling in the first intensive warming period of 4 days. The highest value of $C$. acicula population density was observed during the second temperature peak. These findings thus suggested that higher water temperature could be one of the essential environmental conditions for the outbreak of $C$. acicula in Daya Bay, or at least facilitated their accumulating in sea surface.

\section{Salinity}

Marine holoplanktonic invertebrates are cold-blooded and have body fluids isotonic with the surrounding water. For this reason they are limited to the narrow salinity ranges of oceanic water and have a limited tolerance to changes in salinity. Most species cannot survive in waters such as Black Sea, deltaic or estuarian regions where salinities are much lower than those of open ocean waters. Whereas, a few species including epiplanktonic Creseis spp. and Limacina trochiformis (d'Orbigny) have a better adaption to salinity variation and lower salinity. In Daya bay, there were heavy rains from May 18 to June 92020 (http://www.tianqihoubao.com/weather/top/shenzhen.html), which induced a quick drop of surface water salinity. Based on buoy measurements, the surface water salinity decreased approximately 3 within 3 days and maintained at a low level for about 2 weeks until June 24 (Fig. 6). As mentioned above, compared with other pteropods, Creseis species are known to be able to tolerate violent fluctuations of water salinity as well as lower salinity, therefore, it is possible that $C$. acicula survived in this rainy season, while its competitor or predator did not. Therefore, this could be another possible trigger for the C. acicula bloom.

\section{Food availability}

The food availability could also be an essential factor for the outbreak of $C$. acicula. The food of pteropods like that of most plankton feeders is composed of phytoplankton and protozoa such as diatoms, dinoflagellates and minute crustaceans. It is noteworthy that in Daya Bay, coincident with the temperature increase, the concentration of Chla collected from the samae buoy jumped from $0.96 \mathrm{mg} \mathrm{m}^{-3}$ on June 9,2020 , to $5.53 \mathrm{mg}$ $\mathrm{m}^{-3}$ on June 10, 2020, and maintained at a relatively high level of $>1 \mathrm{mg} \mathrm{m}^{-3}$ for one week, which might be attributed to high loads of nutrients from runoff induced by heavy rainfall (Fig. 6). It suggested that there is a high supply of food resources for C. acicula, who feeds on phytoplankton and protozoa.

\section{Reproductive capability}

The capacity to produce a large amount of larva is an essential necessity for the outbreak of a species' bloom. 
C. acicula has this capability partly contributed to its parthenogenetic behaviour. Based on our laboratory observation, one single $C$. acicula can produce one or more "egg capsules" in a reproductive cycle, each capsule contains as many as 700-1000 oosperms. Therefore, C. acicula population probably can always produce huge amount of oosperms, however, the vast majority cannot develop into larva stage or cannot grow up into mature individuals under natural conditions. They dead either due to rigorous environmental conditions or eaten by predator. Hence, we may can assume that the environment conditions of the bay in June and/or theretofore were suitable or tolerable for C. acicula, while did not for its competitor or predator, therefore, huge number of individuals survived and the bloom was formed.

In conclusion, the abundance of $C$. acicula is controlled by various physical and chemical parameters of the environment, such as temperature, salinity, food, and biological parameters such as competitor and predator. For the present case in Daya bay, higher temperature and Chl $a$, and lower salinity may have possibly triggerred this event. However, not a single condition on its own could have caused the outbreak. Most likely, these conditions combined with other unknown factors led to such a tremendous surge in the amount of $C$. acicula. Unfortunately, till now, there is very limited information on the life history, physiological metabolism, and feeding habit of C. acicula. The specific inherent mechanism triggering such an intensive bloom of $C$. acicula remains unknown. The possiblities of a second surge of C. acicula in Daya Bay, its occurrences of blooms elsewhere, and its potential of becoming a global recurrent issue like jellyfish certainly deserve attention. To better characterize and understand this organism, test hypothesis raised in this report, and assess possible ecological sequences and second outbreak of C. acicula, our lab analysis and field surveys will continue into the future.

\section{AUTHORSHIP}

Ming Dai and Zhanhui Qi: Investigation, Writing original draft. Lei Zeng, Shufei Zhang, Lingling Wang, Xiaoqing Qin and Xiuli Liao: field investigation, laboratory analysis; Jing Yan: data analysis; Honghui Huang and Shaoling Shang: Funding acquisition, writing, review \& editing.

Declaration of competing interest: There is no competing interest to declare.

\section{ACKNOWLEGMENTS}

This work was supported by the National Key Research and Development Program of China (2018YFC1407501, 2018YFC1407504). We appreciate Zhiming Zhang, Rongjun Shi, Fengxia Wu, Qingxia Liu, Song Jiang, Yangguang Gu, and Xiaohui Zhai for their assistance in field work. We sincerely appreciate Shang Li for his great help in language editing.

\section{REFERENCES}

Albergoni, A. (1975). Addensamento improvviso di Creseis acicula(Rang, 1828) (Gastropoda, pteropoda) in una baia del Mare Ligure. Conchiglie 11, 233-236. (In French)

Anderson, D.M., Glibert, P.M. \& Burkholder, J.M. (2002). Harmful algal blooms and eutrophication: nutrient sources, composition, and consequences. Estuaries , 25, 562-584.

Burgi, C.M. \& Devos, C. (1962). Accumulation exceptionelle deCreseis acicula au long des cites dans la region de Banyuls-sur-Mer. Vie et Milieu ., 13, 391-392. (In French)

Edwards, M., Johns, D.G., Leterme, S.C., Svendsen, E. \& Richardson, A.J. (2006). Regional climate change and harmful algal blooms in the northeast Atlantic. Limnol. Oceanogr., 51, 820-829.

Glibert, P.M., Burkholder, J.M., Kana, T.M., Alexander, J., Skelton, H.M. \& Shilling, C. (2009). Grazing by Karenia brevis on Synechococcus enhances their growth rate and may help to sustain blooms. Aquat. Microb. Ecol ., 55, 17-30.

Glibert, P.M., Mayorga, E. \& Seitzinger, S. (2008). Prorocentrum minimum tracks anthropogenic nitrogen and phosphorus inputs on a global basis: application of spatially explicit nutrient export models. Harmful Algae, 8, 33-38. 
Heisler, J., Glibert, P.M., Burkholder, J.M., Anderson, D.M., Cochlan, W.P., Dennison, W.C., et al. (2008). Eutrophication and harmful algal blooms: a scientific consensus. Harmful Algae, 8, 3-13.

Huisman, J., Codd, G.A., Paerl, H.W., Ibelings, B.W., Verspagen, J.M.H. \& Visser, P.M. (2018). Cyanobacterial blooms. Nat. Rev. Microbiol., 16, 471-483.

Hutton, R.F. (1960). Marine dermatosis: Notes on seabather's eruption with Creseis Acicula Rang (Mollusca: Pteropoda) as the cause of a particular type of sea sting along the west coast of Florida.Arch. Dermatol ., 82, 153-157.

Jackson, J.B.C., Kirby, M.X., Berger, W.H., Bjorndal, K.A., Botsford, L.W., Bourque, B.J., et al. (2001). Historical overfishing and the recent collapse of coastal ecosystems. Science, 293, 629-637.

Kokelj, F., Milani, L., Lavaroni, G. \& Casaretto, L. (1994). Marine dermatitis due to Creseis acicula . J. Eur Acad, Dermatol. Venereol. , 3, 555-561.

Krishna Murthy, K. (1967). Seasonal variation in the plankton of Porto Novo waters, India. Hydrobiologia , 29, 226-238.

Morioka, Y. (1980). Dense population of a pteropod, Creseis acicula (needle sea butterfly) in the neritic waters of the middle Japan Sea. Bull. Jap. Sea Reg. Fish. Res. Lab ., 31, 169-171.

Naomi, T.S. (1988). On a swarm of Creseis acicula Rang (Pteropoda) in the Karwar waters, Indian J. Fish ., 35, 64-65.

Nishimura, S. (1965). Dropletss from the plankton net-xx. "sea stings" caused by Creseis acicula Rang (Mollusca: pteropoda) in Japan.Publ. Seto.Mar. Bioi. Lab.XIII (4), 287-290.

Peter, K.J. \& Paulinose, V.T. (1978). Swarming of Creseis acicula Rang (Pteropoda) in the Bay of Bengal. Indian J. Mar. Sci ., 7, 126-127.

Pillai, S.K. \& Rodrigo, J.X. (1984). Swarming of Cresies aciculaRang (Pteropoda) in the Palk Bay off Mandapam. J. Mar. Bio. Assoc. India ., 21, 178-180.

Richardson, A.J., Bakun, A., Hays, G.C. \& Gibbons, M.J. (2009). The jellyfish joyride: causes, consequences and management responses to a more gelatinous future. Trends Ecol. Evol ., 24, 312-322.

Sakthivel, M. \& Haridas, P. (1974). Synchronization in the occurrence of Trichodesmium bloom and swarming of Creseis acicula Rang (Pteropoda) and Penilia avirostris Dana (Cladocera) in the area off cohin. Mahasagar , 7, 61-64.

Schell, J.M., Goodwin, D.S. \& Siuda, A.N.S. (2015). RecentSargassum inundation events in the Caribbean shipboard observations reveal dominance of a previously rare form. Oceanography , 28, 8-10.

Shi, K., Zhang, Y., Zhou, Y., Liu, X., Zhu, G., Qin, B. \& Gao, G. (2017). Long-term MODIS observations of cyanobacterial dynamics in Lake Taihu: responses to nutrient enrichment and meteorological factors.Sci. Rep ., 7, 40326.

Smetacek, V. \& Zingone, A. (2013). Green and golden seaweed tides on the rise. Nature, 504, 84-88.

Sun, S., Zhang, F., Li, C., Wang, S., Wang, M., Tao, Z., Wang, Y., Zhang, G. \& Sun, X. (2015). Breeding places, population dynamics and distribution of the giant jellyfish Nemopilema nomurai(Scyphozoa: Rhizostomeae) in the Yellow Sea and the East China Sea.Hydrobiologia , 754, 59-74.

Wang, M.Q. (2019). The great Atlantic Sargassum belt. Science, 365, 83-87.

Wang, Z.L., Xiao, J., Fan, S.L., Li, Y., Liu, X.Q. \& Liu, D.Y. (2015). Who made the world's largest green tide in China?-an integrated study on the initiation and early development of the green tide in Yellow Sea.Limnol. Oceanogr ., 60, 1105-1117. 
Xu, G.Z. (1989). Daya Bay Environment and resources. Anhui Science and Technology Press, Hefei. p175212.

Zeng, L., Chen, G.B., Wang, T., Yang, B.Z., Yu, J., Liao, X.L. \& Huang, H.H. (2019). Acoustic detection and analysis of Acetes chinensisin the adjacent waters of the Daya Bay Nuclear Power Plant. J. Fishery. Sci. China. , 26, 1029-1039.

Zhou, M.J., Shen, Z.L. \& Yu, R.C. (2008). Responses of a coastal phytoplankton community to increased nutrient input from the Changjiang (Yangtze) River. Cont. Shelf Res ., 28, 1483-1489.

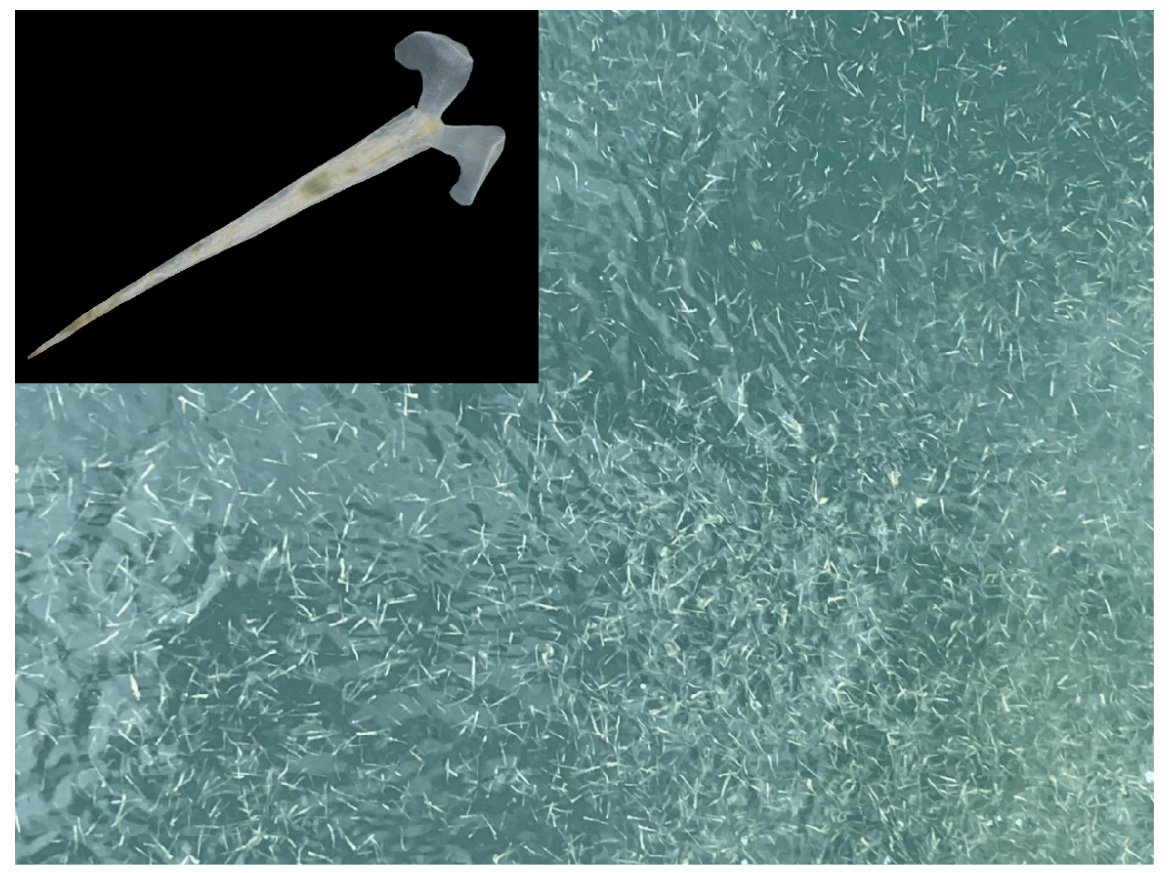

Figure 1 Photographs of Creseis acicula and its accumulation in Daya Bay taken on July 10, 2020.

\section{Hosted file}

image2.emf available at https://authorea.com/users/351926/articles/476342-an-unprecedentedoutbreak-of-pelagic-molluscs-creseis-acicula-in-daya-bay-south-china-sea

Figure 2 Proportion of individuals with different shell lengths in the Creseis acicula population based on a survey on July 4, 2020 in Daya Bay

\section{Hosted file}

image3.emf available at https://authorea.com/users/351926/articles/476342-an-unprecedentedoutbreak-of-pelagic-molluscs-creseis-acicula-in-daya-bay-south-china-sea

Figure 3 Abundance of Creseis acicula from July 4 to 8, 2020 in Daya Bay (The abundance of C. acicula is proportional to the height of the bar in figure legend in which the highest bar represents an abundance of 2800 ind. $\mathrm{m}^{-3}$ ).

\section{Hosted file}

image4.emf available at https://authorea.com/users/351926/articles/476342-an-unprecedentedoutbreak-of-pelagic-molluscs-creseis-acicula-in-daya-bay-south-china-sea 


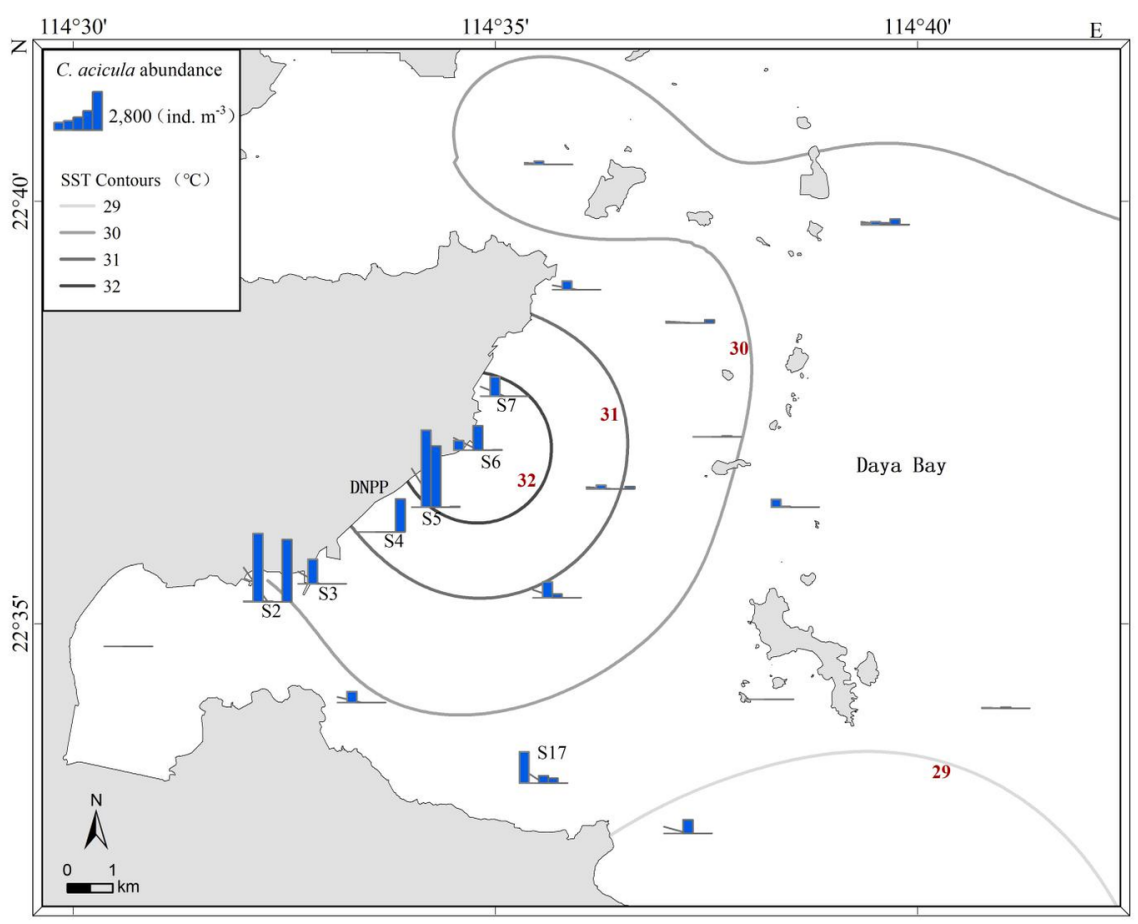

Figure 4 Historical average abundance of Creseis aciculain Daya Bay from 1985 to 2020.

Figure 5 Distribution of Creseis acicula and sea surface temperature (SST, the isotherms) in

southwestern Daya Bay from July 4 to 8, 2020 (The abundance of C. acicula is proportional to the height of the bar in figure legend in which the highest bar represents an abundance of 2800 ind. $\mathrm{m}^{-3}$ )

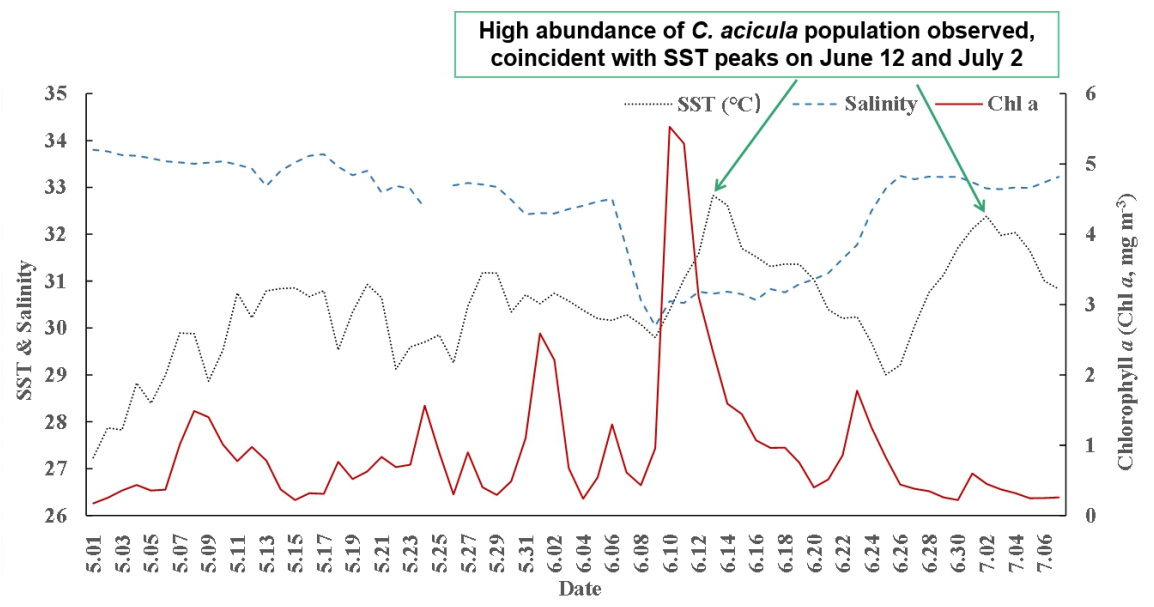

Figure 6 Daily mean sea surface temperature (SST), salinity and chlorophyll $a$ (Chl $a$ ) concentration from May to July 2020 in Daya Bay. 